\title{
A OCORRÊNCIA DOS KNICKPOINTS E SUA RELAÇÃO COM A LITO- ESTRUTURA DO SUBSTRATO GEOLÓGICO NA EVOLUÇÃO DA REDE DE DRENAGEM NO MÉDIO VALE DO PARAÍBA DO SUL
}

\author{
Raphaela Almeida de Souza ${ }^{(a)}$, Stephany Emiliane Lopes da Silva ${ }^{(b)}$, Rodrigo Wagner Paixão \\ Pinto $^{(\mathrm{c})}$, Marcelo Motta de Freitas ${ }^{(\mathrm{d})}$ \\ (a) Graduanda em Geografia e Meio Ambiente/PUC-Rio (raphaelaalmeidas@yahoo.com.br) \\ (b) Graduanda em Geografia e Meio Ambiente/PUC-Rio (stephany-emiliane @ hotmail.com) \\ (c) Doutorando em Geografia e Meio Ambiente/PUC-Rio (rodrigowpp1@gmail.com) \\ (d) Doutor em geomorfologia e professor do quadro principal no dpto de Geografia e Meio Ambiente/PUC-Rio \\ (marcelomotta@puc-rio.br)
}

\section{Eixo: SISTEMAS GEOMORFOLÓGICOS - ESTRUTURAS, DINÂMICAS E PROCESSOS}

\begin{abstract}
Resumo
A faixa móvel Ribeira apresenta estruturas geológicas oriundas principalmente da orogênese Brasiliana e da Abertura do Atlântico. Essas estruturas serão responsáveis pela formação do atual relevo do Planalto Sudeste Brasileiro e irão ordenar a sua rede de drenagem. O objetivo desse trabalho é abordar a ocorrência dos níveis de base locais na formação do médio vale do Paraíba do Sul, mais precisamente na Bacia do Rio Minerva, próximo a cidade de Três Rios - RJ e sua relação com as características do substrato geológico. As observações de campo e análise dos mapeamentos elaborados demonstram que a rede de drenagem do rio Minerva é fortemente controlada pelos lineamentos estruturais e pelos níveis de base locais, seguindo predominantemente a orientação NESW da foliação, intercalando com a orientação NW-SE das estruturas de fraturas.
\end{abstract}

Palavras chave: Controle estrutural. knickpoints. bacia de drenagem. rio Minerva.

\section{Introdução}

A orogênese Brasiliana e o Rift Continental do Sudeste Brasileiro oriundo da Abertura do Atlântico são os principais eventos tectônicos responsáveis pela atual estruturação geológica da faixa móvel Ribeira. A orogênese Brasiliana no precambriano está associada ao metamorfismo de alto grau da crosta terrestre, gerando rochas metamórficas orto e paraderivadas, além da expressiva granitogênese, oriunda da fusão parcial da crosta, marcando a paisagem desde então (HEILBRON, et. al., 2004). Segundo Heilbron (et. al, 1995), a compartimentação tectônica da Faixa Ribeira, estabelecida no seu setor central, compreende quatro terrenos tecto-estratigráficos: Ocidental, Oriental, Paraíba do Sul/Embú e Cabo Frio, que, distribuídos heterogeneamente pelo território do Estado do Rio de Janeiro, constituem um complexo substrato geológico para a evolução subsequente do relevo.

O segundo evento tectônico de natureza rúptil ocorreu por conta de uma intensa atividade de magmatismo básico no Jurássico que culmina com a quebra do Megacontinente Gondwana e, subsequentemente, da abertura do Oceano Atlântico, durando até o Cretáceo, havendo pulsos descontínuos até o Eoceno, 
reativando estruturas antigas. Segundo Riccomini, (et. al.2004), este processo define a consolidação do Rift Continental do Sudeste Brasileiro no cenozoico implicando em uma significativa mudança no relevo sudeste e, consequentemente, nos seus sistemas de drenagens. Em termos estruturais, diversas falhas (N-S) e fraturas (NW-SE/NE-SW) afetaram as estruturas geológicas até então existentes.

A lito-estrutura do substrato geológico irá condicionar a direção e os perfis longitudinais dos canais fluviais, a partir do momento em que promovem a erosão diferencial do relevo. Com isso, são comuns a formação de níveis de base locais, que quando rochosos, são denominados knickpoints e são definidos como degraus topográficos ao longo do perfil longitudinal de um rio, exercendo forte influência nos processos de erosão e sedimentação nas bacias fluviais (Eirado Silva, et.al. 1993).

O trabalho em questão tem como objetivo demonstrar a influência da lito-estrutura do substrato geológico na formação de níveis de base locais ou knickpoints no médio vale do rio Paraíba do Sul. Além disso, a pesquisa buscará investigar futuramente a funcionalidade desses knickpoints na rede de drenagem como controlador dos processos de incisão fluvial e de sedimentação. A área de estudo escolhida como representativa desses processos foi a bacia do rio Minerva, afluente do rio Paraíba do Sul, localizada próximo as cidades de Três Rios (RJ) e Mar de Espanha (MG), no limite interestadual entre Rio de Janeiro e Minas Gerais.

\section{Metodologia}

Primeiramente foi feita uma revisão bibliográfica sobre trabalhos que abrangem fenômenos da evolução da paisagem geomorfológica, tais como as características dos sistemas de drenagens e sua relação com knickpoints. Ainda nesse primeiro momento foi feita uma organização da base de dados georreferenciadas para um posterior mapeamento das feições geomorfológicas na bacia de estudo em um ambiente SIG, através do software ArcGIS, utilizando a base topográfica de 1:50.000 do IBGE que abrangem a região. Após os trabalhos de mapeamentos terem sido realizados, foi feita a identificação e o mapeamento dos knickpoints em ambiente digital, sendo os mais representativos selecionados para uma análise no trabalho de campo. É válido explicar que a identificação dos knickpoints em cartas topográficas se dá nos locais onde há uma concentração de curvas de nível que caracterizam um desnível topográfico abrupto e, também, quando as mesmas se aproximam formando um estrangulamento seguido de desnível para jusante. A partir da identificação de alguns knickpoints em cartas topográficas e outros em trabalho de campo, foram escolhidos como mais expressivos e que mais influem na dinâmica fluvial na bacia os níveis de base localizados no eixo principal correspondente ao rio 
Minerva. Nos trabalhos de campo feitos até o momento três knickpoints dos setes identificados foram descritos a partir da sua litologia e extração de medidas de fraturas e foliação, com bússola Brunton.

\section{Resultados parciais e Discussões}

Entende-se que a lito-estrutura dos substratos geológicos no médio vale do Paraíba do Sul está intimamente relacionada com a formação de knickpoints na região, como mostram estudos de Dantas (et. al., 1995) e Eirado Silva (et.al., 1993) em Bananal-SP. Acreditamos que a evolução da rede de drenagem está intimamente relacionada com a geologia local, justamente por conta das interações dos processos intempéricos utilizando-se de planos de fraqueza nas rochas, modelando o relevo a partir das orientações da rede de drenagem. As observações de campo e os mapeamentos geológico-geomorfológicos mostram de uma forma geral uma relação muito próxima entre a orientação dos canais fluviais e as estruturas litológicas, definindo uma forte orientação de drenagem principal NNE-SSW, seguindo a foliação e das drenagens tributárias seguindo, NW-SE e NE-SW, sob orientação de fraturas. Castanheira (et. al., 2006) em estudos anteriores na área de estudo, acredita que "são as estruturas litológicas principalmente falhas, fraturas e foliação, que acabam concentrando os fluxos de água com maior facilidade, devido à fragilidade oferecida à ação intempérica e erosiva da água".

A litologia da bacia do rio minerva é formada por rochas de quatro unidades: os ortogranulitos do Complexo Juiz de Fora, o Biotita gnaisse bandado do Complexo Paraíba do Sul; Granada-biotita gnaisse da Megassequência Andrelândia e os ortognaisses do Complexo Quirino (TUPINAMBÁ et. al., 2007; VALLADARES, et. al., 2012). Em termos estruturais, tal processo colisional leva as unidades litológicas a um alinhamento de orientação NNE, além de falhas inversas compressivas e outras transcorrentes de acordo com o regime de esforços. Somado a isso, o esforço crustal proveniente da tectônica rúptil formadora do Rift Sudeste desenhou fraturas em diversas direções, bem como alinhamento de raros diques básicos. A figura 1 demonstra que a orientação da rede de drenagem do rio Minerva segue os lineamentos estruturais mapeados, apoiando a afirmação de Castanheira op.cit. sobre o controle das estruturas litológicas na dinâmica fluvial de uma bacia.

No total foram mapeados 42 knickpoints na bacia. A partir do mapa de distribuição de knickpoints (figura

2) é possível observar que há uma grande concentração nas porções norte e oeste da bacia, próximos de suas cabeceiras, apresentando grandes amplitudes de relevo. 

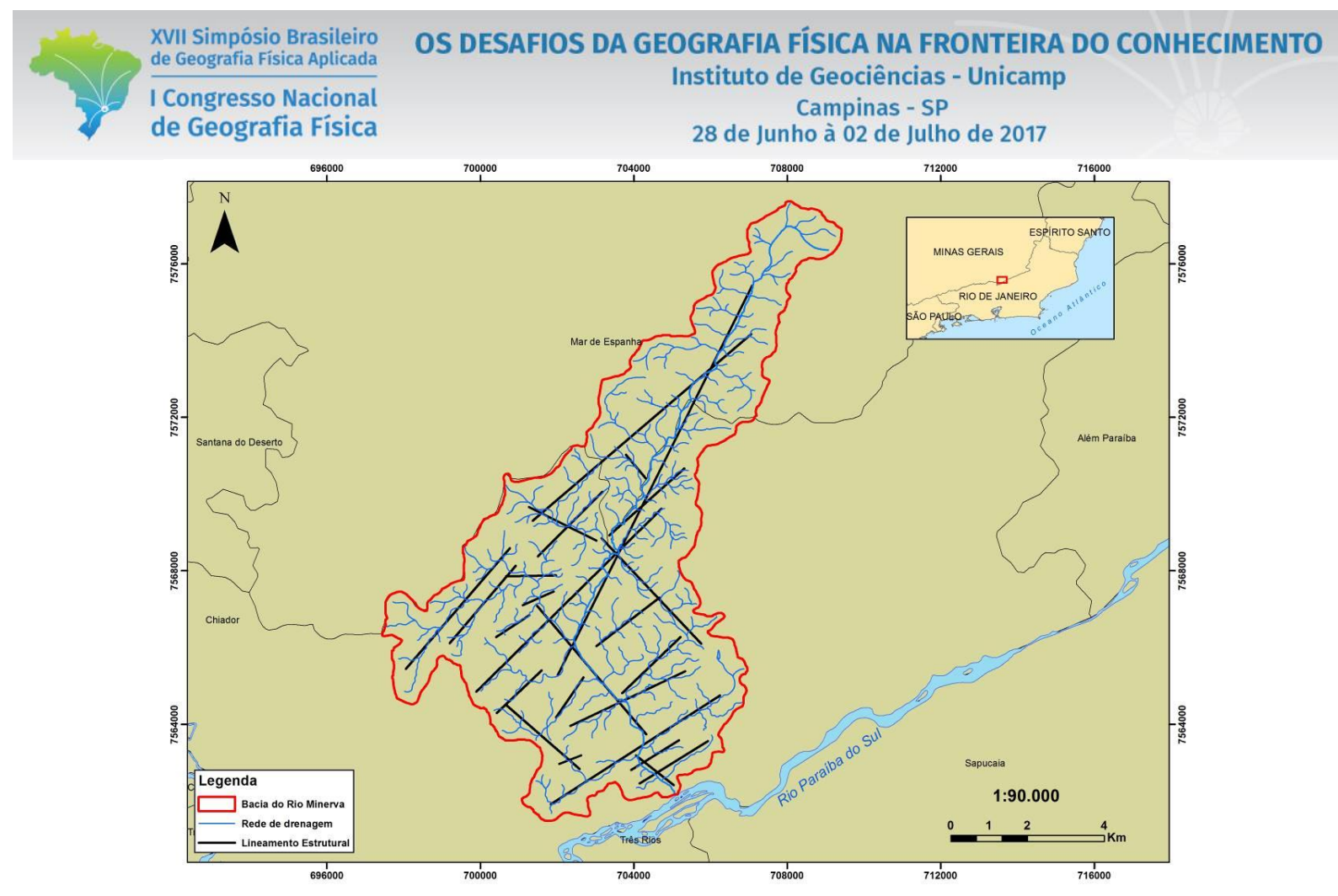

Figura 1 - Lineamento estrutural controlando a orientação da rede de drenagem da Bacia do Rio Minerva.

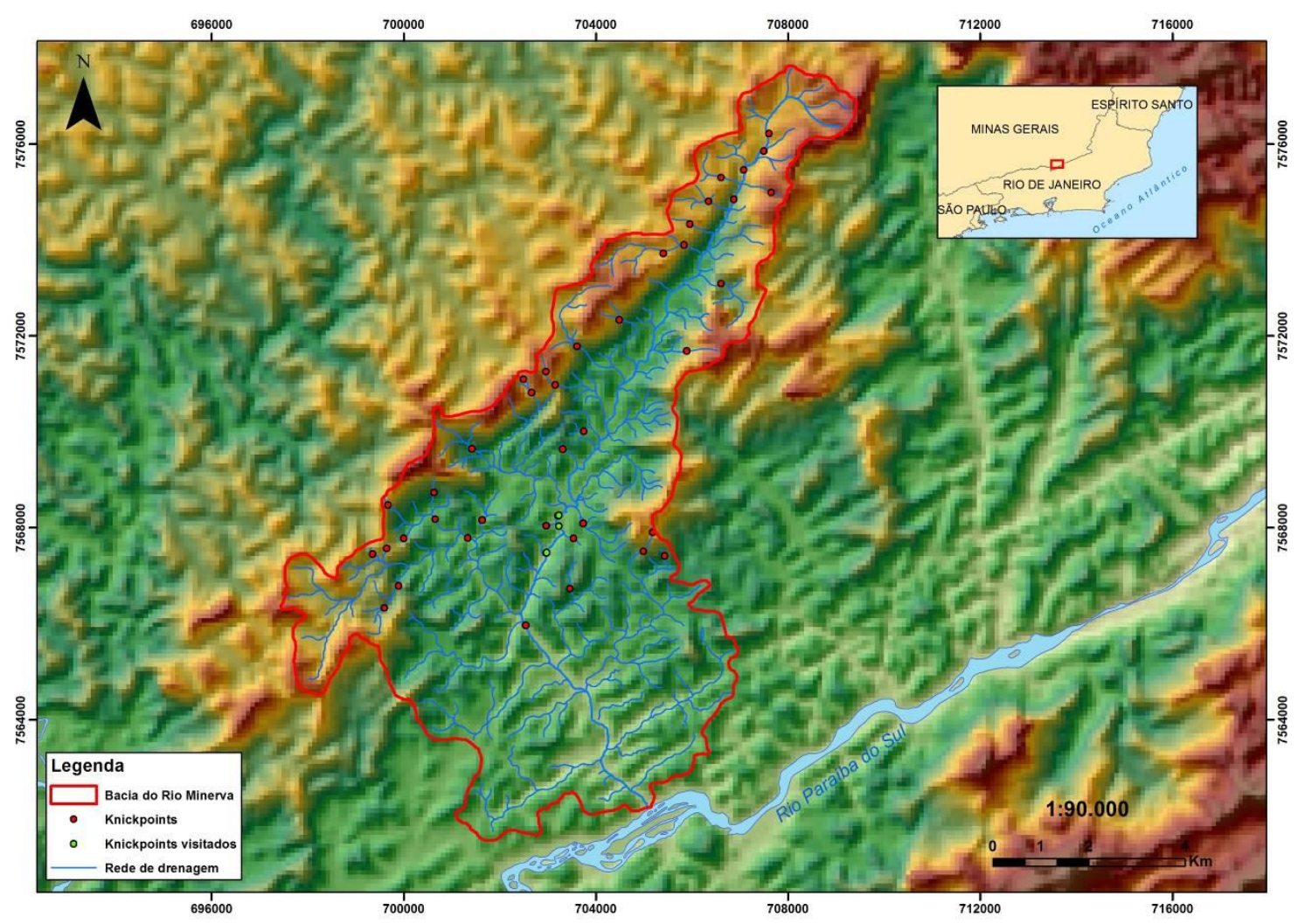

Figura 2 - Mapa da distribuição de knickpoints na bacia do Rio Minerva. 
Os gnaisses metassedimentares do Complexo Paraíba do Sul e Grupo Andrelândia apresentam uma resistência ao intemperismo relativamente menor aos ortogranulitos do Complexo Juiz de Fora e aos ortognaisses do Complexo Quirino. A foliação NE-SW desses metassedimentares e sua composição litológica facilitaram o recuo erosivo do eixo principal, inclusive com a formação de um relevo de colinas na porção central da bacia e expressivos depósitos sedimentares fluviais nos fundos de vale, denominados como alvéolos.

Com base nas análises de campo, a litologia predominante no eixo principal do rio Minerva é composta pelos metassedimentos do Grupo Paraíba do Sul, com ocorrência de sete expressivos knickpoints. Destes sete, foram visitados nesta fase inicial da pesquisa três grandes knickpoints, em forma de corredeiras e cachoeiras, na porção central da bacia:

Ponto 1, (UTM 702960/7567473, zona 23S) mais a jusante - knickpoint formado pela unidade Biotita gnaisse, bandado, de granulometria média, composta por feldspato, quartzo e biotita com distribuição homogênea de cristais em torno de $2 \mathrm{~mm}$, intercalando as fases biotíticas com as fases félsicas. Interceptando esta unidade, um dique mesozoico de diabásio encaixado obliquamente gerou um pequeno degrau topográfico no knickpoint, porém não orientou o fluxo do rio neste trecho, o qual seguia a foliação com orientação $337^{\circ} / 79^{\circ}$ da rocha encaixante.

Ponto 2, (UTM 703116/7568131, zona 23S) na porção central do knickpoint em forma de cachoeira, aproximadamente 800 metros de distância do ponto 1 - a litologia do afloramento rochoso é constituída do mesmo Biotita gnaisse, bandado com bandas de até $2 \mathrm{~cm}$, porém neste caso, intercalado com corpos graníticos em condição migmatítica e presença de veios de quartzo de diversas espessuras no afloramento. No trecho desse knickpoint, o canal é orientado pela foliação $345^{\circ} / 80^{\circ}$, justamente alinhado a NNE, e composto por pequenos saltos formados pelas fraturas de orientação $205^{\circ} / 89^{\circ}$ e $232^{\circ} / 87^{\circ}$ de direção NWSE.

Ponto 3 (UTM 703252/7568266, zona 23S), na cabeceira do knickpoint em forma de corredeira em direção a queda do ponto 2, o mesmo biotita gnaisse aflora com seu bandamento e com a presença de corpos graníticos intercalados em condição migmatítica. A foliação $333^{\circ} / 82^{\circ}$ orienta o fluxo do canal e são abundantes as fraturas no sentido ortogonal a foliação. Esse knickpoint marca um nível de base local interrompendo um longo alvéolo a sua montante, desempenhando seu papel na retenção de sedimentos no transporte fluvial e assim influenciando o desenvolvimento evolutivo da rede de drenagem. 


\section{Considerações Parciais}

A pesquisa se apresenta em estágio inicial, entretanto esse estudo é de significativa importância para o entendimento da funcionalidade e distribuição dos knickpoints na evolução da paisagem geomorfológica da região. A rede de drenagem apresenta expressiva relação com as estruturas do substrato geológico e os knickpoints são controlados pela intercalação das estruturas de foliação e fratura, bem como as ocorrências esporádicas dos diques de Diabásio. Apesar da pesquisa não estar concluída, a partir dos resultados parciais acima já podemos perceber como os knickpoints influenciam expressivamente no controle da orientação da rede de drenagem e na evolução da paisagem da bacia do rio Minerva.

\section{Bibliografia}

CASTANHEIRA, M., FREITAS, M., \& SARTI, T. (2006). Evolução da rede de drenagem controlada por nível de base regional e evidências do processo de captura fluvial no médio vale do rio Paraíba do Sul. In: VI Simpósio Nacional de Geomorfologia/Regional Conference on Geomorphology - Goiânia/GO, 1-10.

DANTAS, M.E.; EIRADO, L.G. \& COELHO NETTO, A.L. Níveis de Base Locais e Estocagem Diferencial de Sedimentos nas Bacias dos Rios Bananal (SP/RJ) e Salto (RJ): controle geológicos e morfométricos. In: Congresso da Associação Brasileira de Estudos do Quaternário - ABEQUA, 5, Anais, Niterói/RJ, p. 176-182, 1995.

EIRADO SILVA, L. G.; DANTAS, M. E. \& COELHO NETTO,A.L. Condicionantes lito-estruturais na formação de níveis de base locais ("knickpoints") e implicações geomorfológicas no Médio Vale do rio Paraíba do Sul . ln: III Simpósio de Geologia do Sudeste - Rio de Janeiro/RJ - Atas, 96-102, 1993.

HEILBRON, M.; PEDROSA SOARES, A.C.; NETO, M.C.C.; SILVA, L.C.; TROW, R.A.J.; JANASI, V.A. (2004). Província Mantiqueira. In: Geologia do Continente Sul-Americano: evolução da obra de Fernando Flávio Marques de Almeida. Editora Beca, São Paulo-SP. Cap. XIII.

HEILBRON, M.; VALERIANO, C.M.; VALLADARES \& C.S.; MACHADO, N. A orogênese brasiliana no segmento central da faixa Ribeira, Brasil. Revista Brasileira de Geociências, 25(4): 249-266, 1995.

RICCOMINI, C., SANT'ANNA, L. G., \& FERRARI, A. L. Evolução geológica do rift continental do sudeste do Brasil. Geologia do continente Sul-Americano: evolução da obra de Fernando Flávio Marques de Almeida, 383-405, 2004.

TUPINAMBÁ, M. et al. Geologia da Faixa Ribeira Setentrional: estado da arte e conexões com a Faixa Araçuaí. Revista Geonomos, v. 15, n. 1, 2013.

VALLADARES, C. S. et al. Geologia e recursos minerais da folha Três Rios SF.23-Z-B-I: escala 1:100.000: estado do Rio de Janeiro. Belo Horizonte: CPRM, 2012. 